\title{
Probiotic Efficacy and Potential of Streptococcus thermophilus modulating human health: A synoptic review
}

\author{
Rohit Sharma $^{1 *, 2}$, Bhuwan Bhaskar ${ }^{1}$, Bhagwan S. Sanodiya ${ }^{1}$, Gulab S. Thakur ${ }^{1}$, \\ Pallavi Jaiswal $^{1}$, Nitin Yadav ${ }^{1}$, Anjana Sharma ${ }^{2}$ and Prakash S Bisen ${ }^{1,2}$ \\ $I^{1 *}$ (Microbial Biotechnology Laboratory, R\&D Division, Tropilite Foods Pvt Ltd, Davars Campus, Tansen Road, \\ Gwalior-474002, India) \\ ${ }_{2}^{2}$ (Department of Post Graduate Studies and Research in Biological Sciences, Rani Durgavati Vishwavidyalaya, \\ Jabalpur - 482004, India)
}

\begin{abstract}
The use of probiotic bacterial cultures stimulates the growth of preferred microorganisms, crowds out potentially harmful bacteria, and reinforces the body's natural defence mechanisms. Streptococcus thermophilus has been exploited industrially for making cheese as well as yogurt. One of the most important properties of this bacterium which is being used is production of lactase, an enzyme that converts lactose (milk sugar) into a simple sugar, which helps people who are lactose intolerant to digest milk. So consumption of this microbe has facilitated to alleviate symptoms of lactose intolerance and other gastrointestinal problems. Due to this unique feature of the microbe, it has been added to several health supplements along with other bacteria with similar properties. Over and above, it also produces a variety of antagonistic factors that include metabolic end products, antibiotic-like substances and bactericidal proteins, termed bacteriocins which assist to prevent several types of infections from various pathogenic microbes. In addition, the bacterium is endowed with enormous important beneficial properties. The following review will discuss with some beneficial aspects of S. thermophilus.
\end{abstract}

Key Words: Streptococcus thermophilus, Probiotic, Lactose intolerance, Microflora, Dysbiosis, Bacteriocins

\section{Introduction}

The term probiotic means "for life" and it denotes the bacteria beneficial for humans and animals. The original observation of the positive role played by some selected bacteria is attributed to Elie Metchnikoff, the Russian born Nobel Prize recipient working at the Pasteur Institute, who suggested that "The dependence of the intestinal microbes on the food makes it possible to adopt measures to modify the flora in our bodies and to replace the harmful microbes by useful microbes"[1]. Fuller (1989) [2], pointing out towards the microbial nature of probiotics, redefined the term as "A live microbial feed supplement which beneficially affects the host animal by improving its intestinal balance". A more recent, but probably not the last definition is "live microorganisms, which when consumed in adequate amounts, confer a health effect on the host" [3]. Exploiting the probiotic bacteria has been proved beneficial as a potential preventive measure by providing a microbial stimulus to the host immune system by administering microorganisms that are characteristics of the healthy, human gut microflora. And as such research diversifies; one particular bacterial strain has attracted and is receiving special attention - Streptococcus thermophilus which comes to our diet through variety of fermented products. S. thermophilus is a Gram-positive bacterium belonging to the phylum Firmicutes, family Streptococcaceae and order Lactobacillales. It belongs to the clade of Lactic acid bacteria which include the species of genera Carnobacterium, Enterococcus, Lactobacillus, Lactococcus, Leunostoc, Oenococcus, Pediococcus, Tetragenococcus, Vagococcus and Weissella [4]. S. thermophilus is closely related to Lactococcus lactis, but it is even more closely related to other streptococcal species including several pathogens [5]. $S$. thermophilus is highly adapted to grow on lactose, the main carbon source in milk and rapidly converts it into lactate during growth. Lactose is transported into the cell by a lactose permease (LacS), which operates as a galactosideproton symport system or as a lactose-galactose antiporter. Lactose is efficiently transported into the cell and subsequently hydrolyzed by an intracellular b-galactosidase. The vast majority of $S$. thermophilus strains only metabolized the glucose moiety of lactose, while galactose is excreted into the medium. The milk is poor in free amino acids (AA) and short peptides, therefore for optimal growth; S. thermophilus requires either hydrolysis of caseins followed by the internalization and the degradation of the resulting peptides or de novo AA biosynthesis [6]. For many LAB including $S$. thermophilus, the hydrolysis of milk caseins (i.e. the AA supply) mostly depends on the activity of a cell-wall-anchored proteinase [7]. S. thermophilus and L. bulgaricus, lead to positive effects on the yogurt taste and aroma by symbiotic coexistence, described by the ecological term protocooperation (where two species interact with each other beneficially). Protocooperation is basis for creation of symbiotic relation between the two species (S. thermophilus and L. bulgaricus) and combined metabolism with positive effects on the fermented product. Streptococcus strain produces formic acid promoting 
the growth of the Lactobacillus which, on its turn, provides flavour compounds (acetaldehyde) and the proteolytic activity to keep the Streptococcus strain growing in milk [8]. The genus Streptococcus includes Gram positive bacteria with similar metabolic properties but they live in different habitats and have many physiological differences. In the past two decades, several important Streptococcus species have been reclassified as members of recently named genera Enterococcus and Lactococcus. The only dairy streptococcus remained is S. thermophilus. Streptococci grouped as "oral", "pyogenic" and "other streptococci". "Oral" streptococci are also subdivided into four groups; S. mutans, S. mitis, S. anginosus and S.thermophilus groups [9]. Although $S$. thermophilus is a member of "S. thermophilus group" phylogenetically, it is the only bacterium in Streptococci with dairy origin. The Gram positive and cocci genera sharing the same habitat with $S$. thermophilus includes enterococci, lactococci, pediococci and leuconostocs. The pediococci is readily distinguished from other genera by the tetrad morphology in broth media. Some of the physiological differences which are helpful for the first grouping at the genus level are given in the table below:

Table: Classification of cocci lactic acid bacteria

\begin{tabular}{|c|c|c|c|c|c|c|c|}
\hline Microrganism & $\begin{array}{l}\text { Growth } \\
\text { at } 10^{\circ} \mathrm{C}\end{array}$ & $\begin{array}{l}\text { Growth } \\
\text { at } 45^{\circ} \mathrm{C}\end{array}$ & $\begin{array}{l}\text { Growth in } \\
6.5 \% \mathrm{NaCl}\end{array}$ & $\begin{array}{c}\text { Type Lactate } \\
\text { formed }\end{array}$ & $\begin{array}{l}\text { Gas from } \\
\text { Glucose }\end{array}$ & $\begin{array}{c}\text { Growth in broth } \\
\text { at pH } 9.6\end{array}$ & $\begin{array}{c}\text { Arginine } \\
\text { Hydrolysis }\end{array}$ \\
\hline Enterococcus & + & + & + & ND & - & + & + \\
\hline Lactococcus & + & - & - & $\mathbf{L}$ & - & - & $\mathbf{V}$ \\
\hline Streptococcus & - & + & - & $\mathbf{L}$ & - & - & $\mathbf{V}$ \\
\hline Leuconostoc & + & + & - & D & + & ND & - \\
\hline
\end{tabular}

* ND indicates no data available, $\mathrm{V}$ indicates variable: some produce (+) results and some (-), $\mathrm{L}$ indicates levolactic acid and D indicates dextro-lactic acid

S. thermophilus is highly adapted to the dairy environment, and in the wild. It can only be isolated from dairy products. $S$. waius is a recently identified thermophilic Streptococcus isolated from stainless still pasteurization machinery of milk. It shares many phenotypic characteristics with $S$. thermophilus but can be distinguished by the fermentation of galactose, salicin, cellobiose, maltose, melibiose and D-raffinose [10].

\begin{tabular}{|c|c|c|c|c|c|c|}
\hline \multicolumn{7}{|c|}{ Characteristics of Streptococcus thermophilus B4 isolated from Goat Milk (Sharma et al 2013) [10] } \\
\hline Gram & & Spore & Catalase & Fermentation & Glucose & Nitrate \\
\hline Staining & Cell Morphology & Formation & Activity & Type & Fermentation & Reduction \\
\hline Positive & Cocci in chains & Negative & Negative & Homo & Positive & Negative \\
\hline \multicolumn{7}{|c|}{ Sugar Fermentation Streptococcus thermophilus B4 isolated from Goat Milk (Sharma et al 2013) [10] } \\
\hline Sucrose & Lactose & Maltose & Dextrose & Ribose & Sorbitol & Mannose \\
\hline Positive & Positive & Positive & Positive & Negative & Negative & Positive \\
\hline
\end{tabular}

\section{History And Nomenclature}

The name Streptococcus is derived from the Greek word which means "twisted berry" it is seen under the microscope as a chain that resemble a string of beads. Thermophilus is a Greek term which means heat, referring to an organism that is able to survive extreme cases of heat. Orla-Jensen (1919) [11] was the first to differentiate and describe $S$. thermophilus as a distinct streptococcal species. S. thermophilus is classified as a nonpathogenic, single Streptococcus species to possess a generally recognized as safe (GRAS) status [12]. It is also considered as "the second most important industrial dairy starter after Lactococcus lactis" [13]. Along with the use in manufacturing fermented food, streptococcus is reported to posses probiotic properties in adequate amount conferring a health benefit to the host $[14,15,47]$.

Table1: Characteristics of Lactobacillus bulgaricus \& Streptococcus thermophilus [16]

\begin{tabular}{lcc}
\hline Characteristics of microbes & Lactobacillus bulgaricus & Streptococcus thermophilus \\
\hline Growth on MRS agar at pH 6.3 & Positive & Positive \\
Growth on MRS agar at pH 5.4 & Positive & Negative \\
Incubation Temperature & $30^{\circ} \mathrm{C}$ & $42^{\circ} \mathrm{C}$ \\
Catalase activity & Negative & Negative \\
Gram reaction & Positive & Positive \\
Cell morphology & Rods & Cocci \\
Colony size & Small & Big \\
Colony shape & Circular, irregular & Circular, \\
Colony colour & Creamy grey & Irregular, Creamy white \\
\hline
\end{tabular}




\section{S. thermophilus As Dairy Starter}

A starter culture can be defined as a microbial preparation of large numbers of cells of at least one microorganism to be added to a raw material to produce a fermented food by accelerating and steering its fermentation process. $S$ thermophilus is extensively used in starter cultures for dairy products like Swiss and Italian-type cheeses, Gouda cheese and yoghurt because of its metabolical traits such as production of lactic acid, flavouring compounds, exopolysaccharide production, fermentation of galactose, urease and proteolytic activity, [17]. A recent study conducted at National Dairy Research Institute, India shows that $S$ thermophilus isolated from plant sources possess similar physiological and biochemical properties to those from dairy sources and can be considered for developing new starters [52].

\section{Antibacterial Activity Against Intestinal Microbes}

S. thermophilus along with other probiotic bacteria possess inhibitory effects on some of intestinal pathogenic organisms and hence it is evident that it can be administered in order to prevent or ameliorate some diseases.

Table 2: Measurement of antimicrobial activity (zone of inhibition in $\mathrm{mm}$ ) of Lactobacillus bulgaricus and Streptococcus thermophilus against clinical isolates. (Adapted from [16])

\begin{tabular}{cc}
\hline Indicator organisms & Zone of inhibition(in mm) \\
\hline Escherichia coli & 4.0 \\
Klebsiella sp. & 4.2 \\
Pseudomonas sp. & 1.6 \\
Proteus sp. & 2.3 \\
Salmonella sp. & 0 \\
Shigella sp. & 1.8 \\
\hline
\end{tabular}

\section{Efficacy Against Antibiotic Associated Diarrhoea}

In a study conducted to determine the efficiency of probiotic drink (containing S. thermophilus along with Lactobacillus casei, and L. bulgaricus) for the prevention of diarrhoea associated with use of antibiotics and that caused by Clostridium difficale, it was found to reduce the incidence of AAD and also having the potential to decrease morbidity, healthcare costs and mortality if used routinely in patients of age greater than 50 [18].

\section{Efficacy Against Rotavirus Induced Diarrhoea In Infants}

Rotavirus-induced diarrhea poses a worldwide medical problem in causing substantial morbidity and mortality among children in developing countries, and the development of preventive measures remains an important goal. In a double-blind, placebo-controlled trial, infants aged 5-24 months who were admitted to a chronic medical care hospital were randomised to receive a standard infant formula or the same formula supplemented with Bifidobacterium bifidum and S. thermophilus. It was found that the supplementation of infant formula with B. bifidum and $S$ thermophilus can reduce the incidence of acute diarrhoea and rotavirus shedding in infants admitted to hospital [19].

\section{Role In Enteric Dialysis For Renal Failure}

In a test conducted for the formulation of commensal and food grade bacteria that when ingested may become gut flora that catabolize nitrogenous toxins that accumulate in uremia flow into the gut by passive diffusion, an isolate $S$. thermophilus $\mathrm{KB} 19$ reduced urea concentration from $300 \mathrm{mg} / \mathrm{dL}$ to $20 \mathrm{mg} / \mathrm{dL}$ within 24 hours at $\mathrm{pH} 6.3$ when inoculated in Artificial Intestinal Fluid at initial density of $10^{9} \mathrm{cfu} / \mathrm{ml}$. KB19 survived 3 hours in acidic pH 3.0 with only two logs loss in cfu and was able to pass through bile. In addition, this strain evinced no resistance to 8 commonly used antibiotics. These data indicate that $S$. thermophilus bacterial isolate can be used as a urea-targeted component in an enteric dialysis formulation [20].

\section{S. thermophilus for Skin Ailments}

One of the most significant health benefits associated with the use of $S$. thermophilus bacteria in humans is the bacterium's ability to exert a positive effect upon the body's ceramide (a skin protective agent) levels. As shown in a recent study, which demonstrated the efficacy of the bacterium in vitro and in vivo? In vitro, it has shown a considerable positive impact on the ceramide levels measured in cultured human keratinocytes which have function in the formation of a barrier against environmental damage such as pathogens, heat, UV and water loss. Secondly in vivo, it has shown an equally beneficial effect on the level of 
ceramides in stratum corneum, which forms a barrier to protect underlying tissue from infection, dehydration, exposure to chemicals and mechanical stress [21]. Additionally, S. thermophilus has been found to positively influence the levels of sphingolipids in human skin. A study which looked at about 11 patients who were treated with topical creams containing S. thermophilus, in all cases there were "significant improvements in levels of bacterial sphingomyelinase" [22].

\section{Reduction In Colonization Of Nasal Pathogenic Bacteria}

As obtained a study which looked upon the specific measurement of pathogenic bacteria in human nasal canals, the results showed that those patients who were given the supplemented yogurt experienced a markedly reduced level of nasal colonization of pathogenic bacteria - Staphylococci aureus, Streptococcus pneumonia and $\beta$ haemolytic streptococci [23].

\section{S. thermophilus In Cholestrol Assimilation}

Fifty four volunteers participated in a randomised cross over trial; the results of which revealed reductions of between 5-10\% in serum cholesterol levels after several weeks of moderate consumption of yoghurt fermented with L. bulgaricus and S.thermophilus [24].

\section{S. thermophilus As Antioxidant}

The damage caused to our cells and tissues by the free radicals has a critical role in progression of disease and process of ageing. Antioxidants act as first line of defence against the damage caused due to free radicals and thus are vital for optimal health maintenance. The antioxidant defence mechanism in the body is composed not just of endogenousantioxidants but also of exogenous antioxidants from several food sources (vitamins C and E,carotenoids, pholates, flavonoids, phytoestrogens and selenium). It has been recently demonstrated that the probiotic microorganisms can effectively trap reactiveforms of oxygen as such in the experiment conducted using rats which were deficient in vitamin $\mathrm{E}$, has revealed that theintracellular extract from Lactobacillus sp. recovers this deficiency. The classical yoghurt bacteria L. bulgaricus and S. thermophilus inhibit peroxidation of lipids through scavenging the reactive oxygenradicals, such as hydroxyl radical, or hydrogen peroxide [25].

\section{Mucositis In Rats}

A 2009 study in Adelaide, Australia has shown very positive results when S. thermophilus TH-4 was used to treat rats with mucositis (inflammation and ulceration of the mucous membranes) caused by chemotherapy drugs. Rats responded to the treatment by showing a normalization of healthy cell function in the affected areas and a significant reduction of distress to the tissue of the intestines [26]

\section{S. thermophilus In Folic Acid Production}

While growing in milk, $S$. thermophilus is found to produce folic acid which is essential for numerous biological functions and becomes a vital component of yoghurt [27, 28].

\section{S. thermophilus Against Bacterial Vaginosis}

Bacterial vaginosis (BV) is the most common vaginal infection in reproductive aged women. This infection occurs when predominantly anaerobic bacteria such as Gardnerella vaginalis, as well as Mycoplasma hominis, Prevotella and Peptostreptococcus replace the dominant and normal Lactobacillus bacteria in the vagina. One hundred twenty healthy Chinese women with a history or recurring bacterial vaginosis (BV) were randomly assigned to a daily vaginal probiotic capsule as prophylaxis that contained 8 billion colony forming units of Lactobacillus rhamnosus, L. acidophilus and S. thermophilus or a daily vaginal placebo capsule. Women were to insert the capsule 7 days on, 7 days off and 7 days on. Probiotic prophylaxis resulted in lower recurrence rates for BV (15.8\% [9/57 women] vs 45.0\% [27/60 women]; P < .001) and Gardnerella vaginalis incidence through 2 months $(3.5 \%$ [2/57 women] vs $18.3 \%$ [11/60 women]; $\mathrm{P}=.02)$. Between the 2- and 11month follow-up periods, women who received probiotics reported a lower incidence of BV and $\mathrm{G}$ vaginalis. Aside from vaginal discharge and malodour, no adverse events were reported in either study group [43].

\section{Bacteriocin Production By S. thermophilus}

Bacteriocins are proteins produced by certain bacteria having a characteristic feature of inhibiting the growth of similar or closely related bacterial strains The incorporation of bacteriocins as a biopreservative ingredient into model food systems has been studied extensively and has been shown to be effective in the control of pathogenic and spoilage microorganisms [29]. Several strains of $S$. thermophilus have been found to produce bacteriocins which are being discussed in the following table: 
Table 3: Summary of bacteriocins obtained from $S$. thermophilus and their antimicrobial activity

\begin{tabular}{|c|c|c|c|}
\hline Strain & Bacteriocin & $\begin{array}{c}\text { Inhibitory Action } \\
\text { against }\end{array}$ & Reference \\
\hline S. thermophilus ST134 & Thermophilin A & sensitive cells in the culture & {$[30,31]$} \\
\hline S. thermophilus 347 & Thermophilin 347 & Listeria monocytogenes & [32] \\
\hline S. thermophilus Sfi 13 & Thermophilin 13 & L. monocytogenes & [33] \\
\hline S. thermophilus 81 & Thermophilin 81 & Lactococcus lactis, S. typhimurium, E. coli, & [34] \\
\hline S. thermophilus ACA-DC 0040 & Thermophilin $\mathrm{T}$ & Clostridium sporogenes, C. tyrobutyricum & [35] \\
\hline S. thermophilus ACA-DC0001 & Thermophilin ST-1 & $\begin{array}{l}\text { L.innocua,Staphylococcus } \\
\text { aureus, Enterococcus faecalis }\end{array}$ & [36] \\
\hline S. thermophilus 580 & Thermophilin 580 & C. tyrobutyricum & [37] \\
\hline S. thermophilus ST110 & Thermophilin 110 & Pediococcus acidilactic & [38] \\
\hline S. thermophilusSBT1277 & Thermophilin 1277 & C. butylicum, C. sprogenes, B. cereus & [39] \\
\hline S. thermophilus LMD-9 & Thermophilin 9 & L. monocytogenes & [40] \\
\hline S. thermophilus CHCC3534 & & S. typhimurium, S. aureus & [41] \\
\hline S. thermophilus B59671. & Thermophilin 110 & Pediococcus acidilactic & [42] \\
\hline
\end{tabular}

Table 4: Few Probiotic example activities of Streptococcus thermophilus

\begin{tabular}{lll}
\hline Probiotic Activity & Strain & Reference \\
\hline Suppression of Ulcerative colitis & S. thermophilusST28, S.thermophilus ATCC 19258 & {$[48]$} \\
Lactose digestion & S.thermophilus MUH 341 & {$[49]$} \\
Decrease in blood pressure & S. thermophilus TMC 1542 & {$[50]$} \\
Reduction in Blood cholesterol & S.thermophilus & {$[51]$} \\
Anti-gastric activities & S.thermophilus CRL 1190 & {$[46]$} \\
Against Chronic gastritis & S.thermophilus CRL 1190 & {$[45]$} \\
Anti-tumor activity & S.thermophilus & {$[53]$} \\
Anti-listerial activity & S.thermophilus & {$[54]$} \\
Food Preservative & S.thermophilus CCHC 3534 & {$[55]$} \\
\hline
\end{tabular}

\section{Stable Growth In Children}

Food supplements containing $S$ thermophilus have been found to maintain a stable growth rate in children. Children consuming S. thermophilus containing supplements had shown better growth during a 6month period than children who did not receive the supplement [44].

\section{Biotherapeutic}

S. thermophilus is found to be potentially therapeutic against the associated chronic gastritis (ASA) [45] Gastritis is a common disorder in which discontinuity of the gastric mucosa is observed. It is caused by various factors like excess alcohol, infection, intensive consumption of anti-inflammatory drugs with Helicobacter pylori or may be stress. Also, ASA affects various mucosal defence lines such as bicarbonate secretion, mucus synthesis, and decrease of mucosal blood flow. The first therapeutic effect of the fermented milk with the polymer producing strain of $S$. thermophilus on chronic gastritis induced by ASA in mice. It was able to generate immune response in mice and increased the thickness of the gastric mucus gel layer. Studies suggest that recombinant lactic acid bacteria are the excellent candidates for the production of various bio therapeutic proteins and also their delivery to specific places of requirement within the gastrointestinal tract [46, 47]

\section{Conclusion}

It is evident from several studies that, $S$. thermophilus has the potential to be majorly beneficial to human health. Studies have already indicated many positive results stemming from $S$. thermophilus. As such research moves forward, other findings are attracting attention of scientists, such as the suggestion that food stuff containing such bacteria may have anti-carcinogenic cancer-fighting properties as well. For this reason, promoting a superior understanding of human health as it relates to the adequate balance of bacteria in the body is extremely important and warrants further research and investigation. Additionally, role of this bacterium is continuously expanding from use in health maintenance and supplementation in the event of dysbiosis 
(microfloral imbalance) during antibiotic therapy, to a wide range of health applications including skin ailments. With the increase in knowledge and exploring other strains of importance, future trends envisage their increased inclusion in dietary supplements and food stuff that target to a diverse preventive measure in health maintenance needs. Furthermore, there is considerable desideratum to establish the dose which is more effective and strains required for optimal benefit either in a disease state, or as preventive Consequently, far more research is needed before complete implementation but still probiotics seem to be a reliable method of treatment.

\section{References}

[1] Metchnikoff E. Lactic acid as inhibiting intestinal putrefaction. In: The prolongation of life: Optimistic studies. W. Heinemann, London 1907; 161-183.

[2] Fuller R. Probiotics in man and animals J Appl Bacteriol 1989; 66:365-378.

[3] Guarner F, Schaafsma GJ. Probiotics. Int J Food Microbiol 1998; 39: 237-238.

[4] Stiles ME, Holzapfel WH. Lactic acid bacteria of foods and their current taxonomy Int. J Food Microbiol 1997; 36:1-29.

[5] Mitchell TJ. The pathogenesis of streptococcal infections: from tooth decay to meningitis. Nat. Rev. Microbiol. 2003;1:219-230.

[6] Hols, P., Hancy, F., Fontaine, L., Grossiord, B. et al., New insights in the molecular biology and physiology of Streptococcus thermophilus revealed by comparative genomics. FEMS Microbiol. Rev 2005;29:435-463.

[7] Herve-Jimenez L, Guillouard I, Guedon E, Gautier C, Boudebbouze S, Hols P, Monnet V et al. Physiology of Streptococcus thermophilus during the late stage of milk fermentation with special regard to sulfur amino-acid metabolism. Proteomics 2008;8:4273-4286.

[8] Angelov M , Kostov G, Simova E, Beshkova D, Koprinkova P. Proto-cooperation factors in yogurt starter cultures, Revue de genie industriel 2009; 3:4-12

[9] Gobbetti M, Corsetti A. "Streptococcus thermophilus: Introduction" in Enyclopedia of Food Microbiology, edited by C. Batt, P. Patel, R. Robinson (Academic Press, United Kingdom) 1999; 2117-2126.

[10] Sharma R, Sanodiya BS, Thakur GS, Jaiswal P, Pal S, Sharma A, Bisen PS. Characterization of lactic acid bacteria from raw milk samples of cow, goat, sheep, camel and buffalo with special elucidation to lactic acid production. British Microbiology Research Journal 2013; 3(4):743-752.

[11] Orla-Jansen, S. The lactic acid bacteria. Copenhagen. 1919.

[12] Burton JP, Wescombe PA, Moore CJ et al. Safety assessment of the oral cavity probiotic Streptococcus salivarius K12. Appl. Environ. Microbiol 2006; 72:3050-3053.

[13] Mayo B, Sinderen D, Ventura M. Genome analysis of food grade lactic acid-producing bacteria: From basics to applications. Curr. Genomics 2008; 9:169-183.

[14] Lebeer S, Vanderleyden J, Keersmaecker SCD. Genes and molecules of lactobacilli supporting probiotic action. Microbiol. Mol. Biol. Rev 2008; 72:728-764.

[15] Khalil R. Evidence for probiotic potential of a capsularproducing Streptococcus thermophilus CHCC 3534 strain. Pol. J. Microbiol $2009 ; 58: 49-55$.

[16] Hassan D. Nandita D. Yada SI, Umaru AD. Lactobacillus bulgaricus and Streptococcus thermophilus as Probiotics on Some Clinical Pathogens. Researcher 2010; 2(11):38-41.

[17] Leroy F, Vuyst LD. Lactic acid bacteria as functional starter cultures for the food fermentation industry. Trend Food Sc Technol 2004; 15(2) 67-78.

[18] Hickson M, D'Souza AL, Muthu N et al. Use of probiotic Lactobacillus preparation to prevent diarrhoea associated with antibiotics: randomised double blind placebo controlled trial, BMJ 2007; 335:80.

[19] Saavedra JM, Bauman NA, Perman JA, Yolken RH, Oung I. Feeding of Bifidobacterium bifidum and Streptococcus thermophilus to infants in hospital for prevention of diarrhoea and shedding of rotavirus. The Lancet 1994; 344:1046-49.

[20] Zelenaia OA, Patel BG, Dheer RS, Ranganathan BSN. Streptococcus thermophilus KB19 is a Potential Component of a Probiotic Regimen Applicable in Enteric Dialysis for Uremia. J American Society of Nephrology 2004; 765.

[21] Marzio L, Cinque B, Cifone M. Effect of the lactic acid bacterium Streptococcus thermophiles on ceramide levels in human keratinocytes invitro and stratum corneum in vivo, The journal of investigative dermatology $1999 ; 113$.

[22] Marzio L, Centi C, Cinque B, Masci S, Giulani M, Arciery A, Zicari L, De Simone C, Cifone M. Effect of the lactic bacterium Streptococcus thermophilus on stratum corneum levels and signs and symptoms of atopic dermatitis patients. Experimental Dermatology 2003; 12.

[23] Gluck U, Gebbers J. Ingested probiotics reduce nasal colonization with pathogenic bacteria (Staphylococcus aureus, Streptococcus pneumonia and $\beta$ haemolytic streptococci) American journal of clinical nutrition 2003; 77.

[24] Berg RD. The indigenous gastrointestinal microflora. Trends Microbiol. 1996; 4:430-435.

[25] Ling MY, Yen CL. Antioxidative ability of lactic acid bacteria. J.Agric.Food Chem.1999; 47:1460-1466.

[26] Whitford EJ, Cummins AG, Butler RN, Prisciandaro LD, Fauser JK, Yazbeck R, Lawrence A, Cheah KY, Wright TH, Lymn KA, Howarth GS. Effects of Streptococcus thermophilus TH-4 on Intestinal Mucositis Induced by the Chemotherapeutic Agent, 5Fluorouracil (5-FU). National Center for Biotechnology Information. 2009.

[27] Rao DR, ReddyAV, Pulusani SR, Cornwell PE. Biosynthesis and utilisation of folic acid and vitamin B12 by lactic cultures in skim milk. Journal of Dairy Science 1984; 67:1169-1174.

[28] Rao DR, Shahani KM. Vitamin content of cultured milk products. Cultured Dairy Products Journal 1987; $22: 6-10$.

[29] O'Sullivan L, Ross RP, Hill C. Potential of bacteriocin-producing lactic acid bacteria for improvements in food safety and quality Biochimie 2002; 84:593-604.

[30] Ward DJ, Somkuti GA. Characterization of a bacteriocinproduced by S. thermophilus ST134. Appl. Microbiol. Biotechnol 1995; 43:330-335.

[31] Whitford MF, McPherson MA, Forster RJ, Teather RM. Identification of bacteriocin-like inhibitors from rumen Streptococcus spp. and isolation and characterization of bovicin 255. Appl. Environ.Microbiol 2001; 67:569-574.

[32] Villani F, Pepe O, Mauriello G, Salzano G, Moschetti G, Coppola S. Antilisterial activity of thermophilin 347, a bacteriocins produced by S. thermophilus. Int. J. Food Microbiol 1995; 25:179-190.

[33] Marciset O, Jeronimus-Stratingh MC, Mollet B Poolman B: Thermophilin 13, a nontypical antilisterial poration complex bacteriocin, that functions without a receptor J Biol Chem. 1997; 272(22):14277-84.

[34] Ivanova I, Miteva V, Stefanova T, Pantev A, Budakov I, Danova S,Moncheva P, Nikolova I, Dousset X, Boyava P. Characterization of a bacteriocin produced by S. thermophilus 81. Int.J. Food Microbiol 1998; 42:147-158. 
[35] Aktypis A, Kalanzopoulos G, Huis in't Veld JHJ Brink B. Purification and characterization of thermophilin T, a novel bacteriocin produced by S. thermophilus ACA-DC 0040. J. App.Microbiol 1998; 84:568-576.

[36] Aktypis A, Kalanzopoulos G. Purification and characterization of thermophilin ST-1, a novel bacteriocin produced by Streptococcus thermophilus ACA-DC 0001. Lait 2003; 83:365-378.

[37] Mathot AG, Beliard E, Thuault D. S. thermophilus 580 produces a bacteriocin potentially suitable for inhibition of C. tyrobutyricum in hard cheese. J. Dairy Sci 2003; 86:3068-3074.

[38] Gilbreth SE, Somkuti GA. Thermophilin 110: A Bacteriocin of S.thermophilus ST110. Current Microbiol 2005; 51:175-182.

[39] Kabuki T, Uenishi H, Watanabe M, Seto Y, Nakajima H. Characterization of a bacteriocin, Thermophilin 1277, produced by S.thermophilus SBT1277. J. Appl. Microbiol 2006; 102:97-980.

[40] Fontaine L, Hols P. The Inhibitory Spectrum of Thermophilin 9 from Streptococcus thermophilus LMD-9 Depends on the Production of Multiple Peptides and the Activity of BlpGSt, a Thiol-Disulfide Oxidase Applied And Environmental Microbiology $2008 ; 1102-1110$.

[41] Khalil R, Evidence for probiotic potential of a capsular producing Streptococcus thermophilus CHCC 3534 strain, Polish Journal of Microbiology 2009; 58:49-58.

[42] John A, Renye Jr, Somkuti GA. BlpC-regulated bacteriocin production in Streptococcus thermophilus, Biotechnol Lett 2013; 35:407-412.

[43] Wang Y, Reifer C, Miller L. Efficacy of vaginal probiotic capsules for recurrent bacterial vaginosis: a double-blind, randomized, placebo-controlled study. Amer J Obst/Gyn 2010; 120.1-120.6.

[44] Nopchinda, S et al. "Effect of Bifidobacterium Bb12 with or without Streptococcus thermophilus Supplemented Formula on Nutritional Status." J. Medical Association of Thailand 2002; 85:1225-1231.

[45] Rodriguez C, Medici M, Mozzi F, Font de Valdez G. Therapeutic effect of Streptococcus thermophilus CRL 1190- fermented milk on chronic gastritis. World J Gastroenterol 2010; 16(13):1622-1630.

[46] Daniel G, Roussel Y, Kleerebezem M,Pot B, Recombinant lactic acid bacteria as mucosal biotherapeutic agents. Trends Biotechnol 2011; 29(10):499-508.

[47] Sharma R, Sanodiya BS, Bagrodia D, Pandey M, Sharma A, Bisen PS. Efficacy and Potential of Lactic acid bacteria modulating human health. IJPBS 2012; 3(4):(B) 935-948.

[48] Ogita T, Nakashima M, Morita M et al. StreptocouuS thermophilus ST28 Ameliorates colitis in mice partially by suppression of inflammatory Th 17 cells. J Biomed Biotechnol 2011; 2011:378417.

[49] Anderson JW, Gilliland SE. Effect of fermented milk (yogurt) containing Lactobacillus acidophilus L1 on serum cholesterol in hypercholesterolemic humans. J Am Coll Nutr. 1999; 18:43-50.

[50] Kawase M, Hashimoto H, Hosoda M, Morita H, Hosono A. Effect of administration of fermented milk containing whey protein concentrate to rats and healthy men on serum lipids and blood pressure. J Dairy Sci. 2000; 83:255-63.

[51] Bertolami MC, Faludi AA, Batlouni M. Evaluation of the effects of a new fermented milk product (Gaio) on primary hypercholesterolemia. Eur J Clin Nutr.1999; 53:97-101.

[52] Mamaheswari TU, Anbukkaras KI, Ingh PS et al. Streptococcus thermophilus strains of plant origin as dairy starters: Isolation and characterisation. International Journal of Dairy Technology 2014; 67.

[53] Kaklij GS and Shashikant Madan Kelkar. Tumor-Specific Transplantation Resistance in Mice after Treatment of Initial Tumors with Streptococcus Thermophilus. Microbiol. Immunol 1996; 40(1):55-58.

[54] Ali JAS, Mahmood NN, Effect of Streptococcus thermophilus supernatant and inulin on Listeria monocytogenes in soft cheese. Food Science and Quality Management.

[55] Khali RK. Evidence for probiotic potential of a capsularproducing Streptococcus thermophilus CHCC 3534 Strain. African Journal of Microbiology Research 2009; 3(1):027-034. 